\title{
Effects of metformin extended release compared to immediate release formula on glycemic control and glycemic variability in patients with type 2 diabetes
}

\author{
This article was published in the following Dove Press journal: \\ Drug Design, Development and Therapy \\ 16 May 2017 \\ Number of times this article has been viewed
}

\author{
Giuseppe Derosa ${ }^{1-4}$ \\ Angela D'Angelo ${ }^{1,4}$ \\ Davide Romano' \\ Pamela Maffioli ${ }^{1,5}$ \\ 'Department of Internal Medicine \\ and Therapeutics, Centre of Diabetes \\ and Metabolic Diseases, ${ }^{2}$ Centre for \\ the Study of Endocrine-Metabolic \\ Pathophysiology and Clinical \\ Research, ${ }^{3}$ Centre for Prevention, \\ Surveillance, Diagnosis and Treatment \\ of Rare Diseases, Fondazione IRCCS \\ Policlinico San Matteo, ${ }^{4}$ Laboratory \\ of Molecular Medicine, ${ }^{5} \mathrm{PhD}$ School \\ in Experimental Medicine, University \\ of Pavia, Pavia, Italy
}

Purpose: The purpose of this study is to evaluate, in a randomized clinical trial, the effects of metformin immediate release (IR) compared with metformin extended release (XR) on the gastrointestinal tolerability and glycemic control.

Materials and methods: We enrolled 253 Caucasian patients with type 2 diabetes not well controlled by diet (glycated hemoglobin $\left[\mathrm{HbA}_{1 \mathrm{c}}\right]>7.0 \%$ and $<8.5 \%$ ). Patients were randomized to metformin IR or metformin XR for a period of 6 months at the maximum tolerated dose. The average dose of metformin IR used was $2,000 \pm 1,000 \mathrm{mg}$ /day, while that of metformin XR was $1,000 \pm 500 \mathrm{mg} /$ day. We evaluated body weight, $\mathrm{HbA}_{1 \mathrm{c}}$, fasting and postprandial glucose, fasting plasma insulin (FPI) and homeostasis model assessment insulin resistance (HOMA-IR), lipid profile, and levels of some adipocytokines, including tumor necrosis factor- $\alpha$ (TNF- $\alpha$ ), high-sensitivity C-reactive protein (hs-CRP), visfatin, and vaspin. Moreover, at the baseline and after 6 months, we administered patients some validated questionnaires to assess patients' satisfaction toward treatments.

Results: After 6 months, both formulations gave a similar reduction in body weight and body mass index (BMI); however, metformin XR gave a greater improvement in glycemic control, FPI, and HOMA-IR, compared with both baseline and metformin IR. A reduction in total cholesterol (TC) and low-density lipoprotein (LDL) cholesterol was observed with metformin XR compared with IR. Levels of TNF- $\alpha$, hs-CRP, and vaspin were reduced by metformin XR but not by the IR formulation. Metformin XR also raised the levels of visfatin.

Conclusion: Metformin XR formulation seems to be more effective than metformin IR in improving glyco-metabolic control, lipid profile, and levels of some adipocytokines in patients with type 2 diabetes mellitus.

Keywords: glycemic control, insulin resistance, metformin immediate release, metformin extended release

\section{Introduction}

In the absence of contraindications, metformin is the first choice drug for the treatment of diabetes. Metformin reduces plasma glucose levels by acting at several levels; metformin reduces hepatic glucose production in the liver by inhibiting gluconeogenesis and glycogenolysis; metformin increases muscular insulin sensitivity by improving the uptake and utilization of peripheral glucose; moreover, metformin slows intestinal absorption of glucose. ${ }^{1}$ Until now, metformin was available as an immediate release (IR) formulation to be taken thrice a day, at dosages of 500, 850, and 1,000 mg, in tablet or powder.
Correspondence: Giuseppe Derosa Department of Internal Medicine and Therapeutics, Centre of Diabetes and Metabolic Diseases, Fondazione IRCCS Policlinico San Matteo, University of Pavia, P.le C. Golgi, 2-27I00, Pavia, Italy Tel +39382526217

Fax +39382526259

Email giuseppe.derosa@unipv.it 
The powder formulation was designed to overcome the problem of the considerable size of the tablets, which made them difficult to swallow, especially for elderly patients or those with dysphagia. We have already studied the powder formulation showing that it increased the degree of patients' satisfaction toward the antidiabetic treatment and led to an improvement in glycemic control. ${ }^{2}$ However, recently, extended-release (XR) metformin has become available. Compared to conventional IR formulation, the XR offers some advantages; first of all the possibility to take the drug once a day and also a better gastrointestinal tolerability, with equal effectiveness. The XR formulation has been designed to allow a more gradual release of the drug in the main absorption site, ie, in the upper gastrointestinal tract, thus improving its tolerability and improving patients' compliance due to a reduction in the frequency of administration and a decrease in adverse events.

However, apart from a review published about the comparison between metformin IR and metformin $\mathrm{XR},{ }^{3}$ no randomized clinical trials have been conducted to directly compare the two formulations. The aim of this study was to evaluate, in a randomized clinical trial, the effects of metformin IR compared with metformin XR on the gastrointestinal tolerability and glycemic control.

\section{Materials and methods Study design}

This randomized, controlled trial was conducted at the Centre of Diabetes and Metabolic Diseases, IRCCS Policlinico San Matteo (Pavia, Italy). The study protocol was approved by the ethical committee of IRCCS Policlinico San Matteo (Pavia, Italy) (P-20120021548), in accordance with the Declaration of Helsinki and its amendments.

The first patient was enrolled on September 10, 2014, and the last patient concluded the study on May 4, 2016. Suitable patients were contacted by the investigators in person or by telephone. All patients provided written informed consent to participate in this study.

\section{Patients}

We enrolled 253 Caucasian patients with type 2 diabetes not well controlled by diet (glycated hemoglobin $\left[\mathrm{HbA}_{1 \mathrm{c}}\right]>7.0 \%$ and $<8.5 \%$ ), aged $\geq 18$ years of either sex (Table 1) according to the European Society of Cardiology (ESC) and European Association for the Study of Diabetes (EASD) Guidelines criteria. ${ }^{4}$

Patients were excluded if they had a history of ketoacidosis or had unstable or rapidly progressive diabetic

Table I Characteristics of enrolled patients treated with Met-IR and Met-XR

\begin{tabular}{|c|c|c|c|c|c|c|}
\hline \multirow[t]{2}{*}{ Characteristics } & Met-IR & Met-XR & Met-IR & Met-XR & Met-IR & Met-XR \\
\hline & \multicolumn{2}{|l|}{ Baseline } & \multicolumn{2}{|l|}{3 months } & \multicolumn{2}{|l|}{6 months } \\
\hline $\mathrm{n}$ & 125 & 128 & 119 & 124 & 115 & 120 \\
\hline $\operatorname{Sex}(M / F)$ & $60 / 65$ & $62 / 66$ & $57 / 62$ & $61 / 63$ & $56 / 59$ & $59 / 61$ \\
\hline Age (years) & $55.8 \pm 10.7$ & $56.5 \pm 11.3$ & $55.8 \pm 10.7$ & $56.5 \pm 11.3$ & $55.8 \pm 10.7$ & $56.5 \pm 11.3$ \\
\hline Height (m) & $1.67 \pm 0.05$ & $1.66 \pm 0.04$ & $1.67 \pm 0.05$ & $1.66 \pm 0.04$ & $1.67 \pm 0.05$ & $1.66 \pm 0.04$ \\
\hline Weight (kg) & $76.1 \pm 5.9$ & $75.8 \pm 5.6$ & $74.9 \pm 5.1$ & $74.1 \pm 4.8$ & $73.4 \pm 4.8^{*}$ & $72.2 \pm 4.2 *$ \\
\hline BMI $\left(\mathrm{kg} / \mathrm{m}^{2}\right)$ & $27.3 \pm 2.1$ & $27.5 \pm 2.4$ & $26.8 \pm 1.7$ & $26.9 \pm 1.8$ & $26.4 \pm 1.4^{*}$ & $26.2 \pm 1.2 *$ \\
\hline Abdominal circ $(\mathrm{cm})$ & $93.5 \pm 3.4$ & $92.8 \pm 3.1$ & $91.8 \pm 3.1$ & $92.0 \pm 3.2$ & $90.2 \pm 2.7^{*}$ & $90.4 \pm 2.9 *$ \\
\hline Waist circ $(\mathrm{cm})$ & $90.6 \pm 4.1$ & $91.2 \pm 4.8$ & $88.5 \pm 3.7$ & $89.7 \pm 4.2$ & $88.4 \pm 3.6$ & $89.2 \pm 3.8$ \\
\hline Hip circ (cm) & $100.7 \pm 6.4$ & $99.6 \pm 5.8$ & $98.4 \pm 5.9$ & $97.5 \pm 5.4$ & $98.6 \pm 6.0$ & $97.1 \pm 5.1$ \\
\hline $\mathrm{HbA}_{\mathrm{Ic}}(\%)$ & $7.7 \pm 0.6$ & $7.6 \pm 0.5$ & $7.3 \pm 0.4^{*}$ & $7.1 \pm 0.3^{*}$ & $7.3 \pm 0.4^{*}$ & $6.8 \pm 0.3 * *, * * *$ \\
\hline FPG (mg/dL) & $144.8 \pm 18.6$ & $146.3 \pm 19.5$ & | 38.5 \pm | 6.4 & $130.9 \pm 14.1 *$ & $|32.8 \pm| 4.4^{*}$ & $|22.3 \pm| \mid .5 * *, * * *$ \\
\hline PPG (mg/dL) & $|82.4 \pm 2| .5$ & $184.7 \pm 23.2$ & $|7| .5 \pm 18.4^{*}$ & $168.7 \pm 17.2^{*}$ & $165.2 \pm 15.3^{*}$ & $151.5 \pm 12.4 * *, * * *$ \\
\hline $\mathrm{FPI}(\mu \mathrm{U} / \mathrm{mL})$ & $18.3 \pm 5.1$ & $18.9 \pm 5.6$ & $16.9 \pm 4.7$ & $17.4 \pm 4.9$ & $17.2 \pm 5.0 *$ & $16.8 \pm 4.5^{*}$ \\
\hline HOMA-IR index & $6.5 \pm 2.9$ & $6.8 \pm 3.2$ & $5.7 \pm 2.2$ & $5.6 \pm 2.1 *$ & $5.5 \pm 2.0 *$ & $5.0 \pm 1.7 * *, * * *$ \\
\hline $\mathrm{TC}(\mathrm{mg} / \mathrm{dL})$ & $185.4 \pm 30.6$ & $188.7 \pm 33.9$ & |79.8土27.| & $177.7 \pm 26.4$ & $176.3 \pm 22.6$ & $168.1 \pm 20.2^{* * * * *}$ \\
\hline LDL-C (mg/dL) & $121.9 \pm 17.1$ & $125.2 \pm 19.3$ & 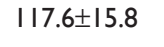 & $120.3 \pm 16.7$ & II3.5 13.4 & $106.4 \pm 11.4 * * * *$ \\
\hline HDL-C (mg/dL) & $42.4 \pm 6.5$ & $41.8 \pm 5.7$ & $42.1 \pm 6.3$ & $42.1 \pm 5.9$ & $43.1 \pm 6.9$ & $43.5 \pm 7.1$ \\
\hline $\mathrm{Tg}(\mathrm{mg} / \mathrm{dL})$ & $105.2 \pm 45.8$ & $108.4 \pm 47.2$ & $100.4 \pm 43.2$ & $101.6 \pm 43.9$ & $98.6 \pm 40.5$ & $90.1 \pm 38.6 *$ \\
\hline Hs-CRP (mg/L) & $2.2 \pm 1.1$ & $2.4 \pm 1.3$ & $2.0 \pm 1.0$ & $1.9 \pm 1.0 *$ & $2.0 \pm 1.0$ & 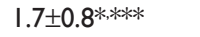 \\
\hline
\end{tabular}

Notes: Data are expressed as mean \pm standard deviation. $* P<0.05$ vs baseline. $* * P<0.01$ vs baseline. $* * * P<0.05$ vs $M$ et-IR.

Abbreviations: Met-IR, metformin immediate release; Met-XR, metformin extended release; $M$, male; F, female; BMI, body mass index; circ, circumference; HbA hemoglobin; FPG, fasting plasma glucose; PPG, postprandial plasma glucose; FPI, fasting plasma insulin; HOMA-IR, homeostasis model assessment insulin resistance index; TC, total cholesterol; LDL-C, low-density lipoprotein cholesterol; HDL-C, high-density lipoprotein cholesterol; Tg, triglyceride; Hs-CRP, high-sensitivity C-reactive protein. 
retinopathy, nephropathy, or neuropathy; impaired hepatic or renal function; or severe anemia. Patients with serious cardiovascular disease (CVD) or cerebrovascular conditions within 6 months before study enrollment were also excluded. Women who were pregnant or breastfeeding or of childbearing potential and not taking adequate contraceptive precautions were also excluded.

\section{Treatments}

Patients were randomized to metformin IR or metformin XR for a period of 6 months at the maximum tolerated dose (considering the onset of gastrointestinal adverse events as a sign of maximum tolerated dose) (Figure 1). The average dose of metformin IR used was 2,000 $\pm 1,000 \mathrm{mg} /$ day, while that of metformin XR was $1,000 \pm 500 \mathrm{mg} /$ day.

Both metformin IR and XR were provided for free by Bruno Farmaceutici (Rome, Italy). Both metformin XR and IR were supplied as identical, opaque, white capsules in coded bottles to ensure the blind status of the study. A description of how randomization and medication compliance were assessed can be found in our previous work. ${ }^{2}$

\section{Diet and exercise}

Subjects began a controlled energy diet ( $\sim 600 \mathrm{kcal}$ daily deficit) based on the American Heart Association (AHA) recommendations. ${ }^{5}$ The characteristics of the diet administered and how diet and physical activity compliance was assessed are mentioned in our previous work. ${ }^{2}$

\section{Assessments}

Before starting the study, all patients underwent an initial screening assessment that included a medical history, physical examination, vital signs, and a 12-lead electrocardiogram. At the baseline and after 3 and 6 months, we evaluated the following parameters: body weight, $\mathrm{HbA}_{1 \mathrm{c}}$, fasting and postprandial glucose, fasting plasma insulin (FPI) and homeostasis model assessment insulin resistance (HOMA-IR), lipid profile, and levels of some adipocytokines, including tumor necrosis factor- $\alpha$ (TNF- $\alpha)$, high-sensitivity C-reactive protein (hs-CRP), visfatin, and vaspin. Moreover, at the baseline and after 6 months, we administered patients the following questionnaires: the SF-36 Health Survey, the Diabetes Quality of Life Modified Questionnaire (DQoL/Mod), and

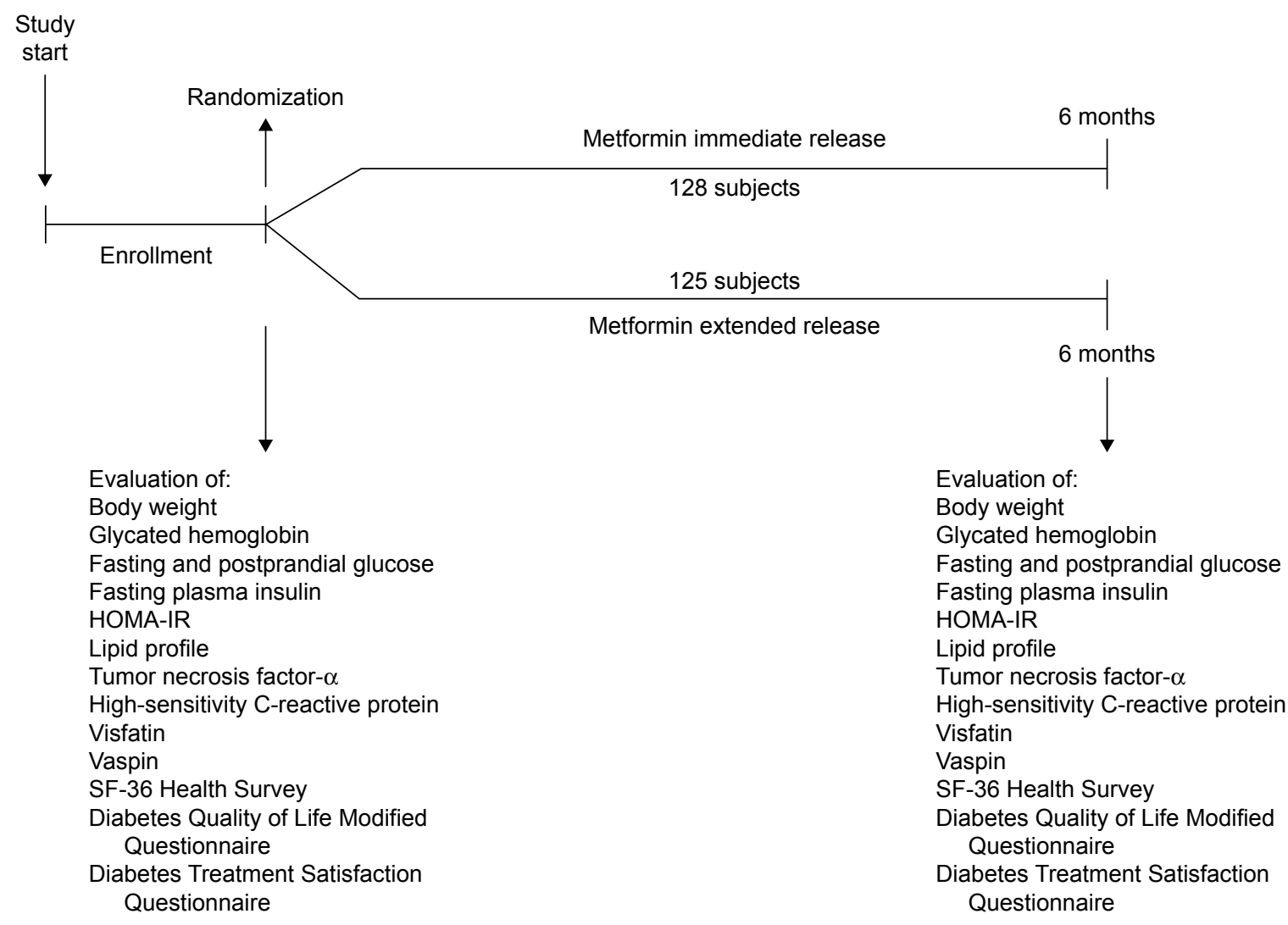

Figure I Study design.

Abbreviations: HOMA-IR, homeostasis model assessment insulin resistance index; SF-36 Health Survey, 36-Item Short Form Health Survey. 
the Diabetes Treatment Satisfaction Questionnaire (DTSQ). All questionnaires were validated in Italian.

A description of how various parameters were assessed is given in our previous work. ${ }^{2,6-8}$ How the various questionnaires were organized is also described in our previous work. $^{2}$

\section{Statistical analysis}

A description of how the statistical analysis was performed is mentioned in our previous work. ${ }^{2}$

\section{Results}

\section{Study sample}

We enrolled 253 patients; 125 were randomized to metformin XR and 128 to metformin IR (Table 1). A total of 235 patients completed the study.

\section{Anthropometric parameters}

After 6 months, both formulations gave a similar reduction in body weight, body mass index (BMI), and abdominal circumference compared to those at baseline $(P<0.05)$, without differences between groups. No variations in waist or hip circumference were recorded in either group.

\section{Glycemic control}

After 3 months, both formulations gave a similar reduction in $\mathrm{HbA}_{1 \mathrm{c}}$ and postprandial plasma glucose (PPG, $P<0.05$ for both compared to baseline, without differences between groups), while only metformin XR decreased FPG compared to that at baseline $(P<0.05)$. However, after 6 months, metformin XR gave a greater reduction in $\mathrm{HbA}_{1 \mathrm{c}}, \mathrm{PPG}$, and FPG compared with both baseline $(P<0.01)$ and metformin IR $(P<0.05)$ (Table 1$)$.

\section{Insulin resistance}

After 6 months, we recorded a significant reduction in FPI and HOMA-IR with both treatments, even if metformin XR had a greater effect in reducing HOMA-IR compared with both baseline $(P<0.01)$ and metformin IR $(P<0.05)$ (Table 1$)$.

\section{Lipid profile}

A reduction in total cholesterol (TC) and low-density lipoprotein cholesterol (LDL-C) was observed with metformin XR compared with IR $(P<0.05$ compared with both baseline and metformin IR) (Table 1). A decrease in triglyceride (Tg) was observed with metformin XR $(P<0.05$ vs baseline) but not with metformin IR. No variations in highdensity lipoprotein (HDL) were recorded (Table 1).

\section{Cytokines levels and hs-CRP}

Levels of TNF- $\alpha$, hs-CRP, and vaspin were reduced by metformin XR $(P<0.05$ vs baseline) but not by the IR formulation. Metformin XR also raised the levels of visfatin $(P<0.05$ vs baseline). Moreover, the levels of TNF- $\alpha$ and hs-CRP were lower, and the levels of visfatin were higher with metformin XR compared to those with IR $(P<0.05$ for all) after 6 months (Table 1 and Figure 2).

\section{Adverse events}

Adverse events were more common with metformin IR formulation, both after 3 months $(P<0.05$ vs metformin $\mathrm{XR})$ and after 6 months $(P<0.01$ vs metformin XR) (Figures 3 and 4).

\section{Questionnaires}

Regarding the SF-36 Health Survey questionnaire, there was an increase in the score of the two questions related to general health perception (question 1: "In general, would you say your health is good?" and question 2: "Compared to 1 year ago, how would you rate your health in general now?"), with a higher score, meaning a better health perception, after the introduction of metformin XR compared to metformin IR. No other significant differences were recorded for the other questions. At the DQoL/Mod questionnaire, instead, after 6 months of metformin XR, there were lower scores, meaning a minor impact of diabetes in the patient life, in questions: 1 ("How much was the quality of your life affected by your diabetes medication schedule?"), 4 (“How much was the quality of your life affected by following your doctor prescribed treatment plan for diabetes?"), 31 ("How much was the quality of your life affected by having your schedule center around diabetes?"), and 39 ("How much was the quality of your life affected by diabetes in general?"). Moreover, there was a greater degree of satisfaction for the metformin XR according to the DTSQ; in particular, there was a higher score in the fields 1 ("How much satisfied are you of your current treatment?"), 4 ("How much did you find comfortable to take your treatment, in the last period?"), 5 ("How did you feel flexible your treatment in the last period?"), 7 (“Would you recommend your treatment to someone else?"), and 8 ("How much would you be satisfied to continue with the current treatment?") (Figure 5). No differences were observed with regard to the fields regarding the perception of hypo- and hyperglycemia.

\section{Discussion}

In our study, we recorded a better effect of metformin XR compared with metformin IR in improving glycemic control. 

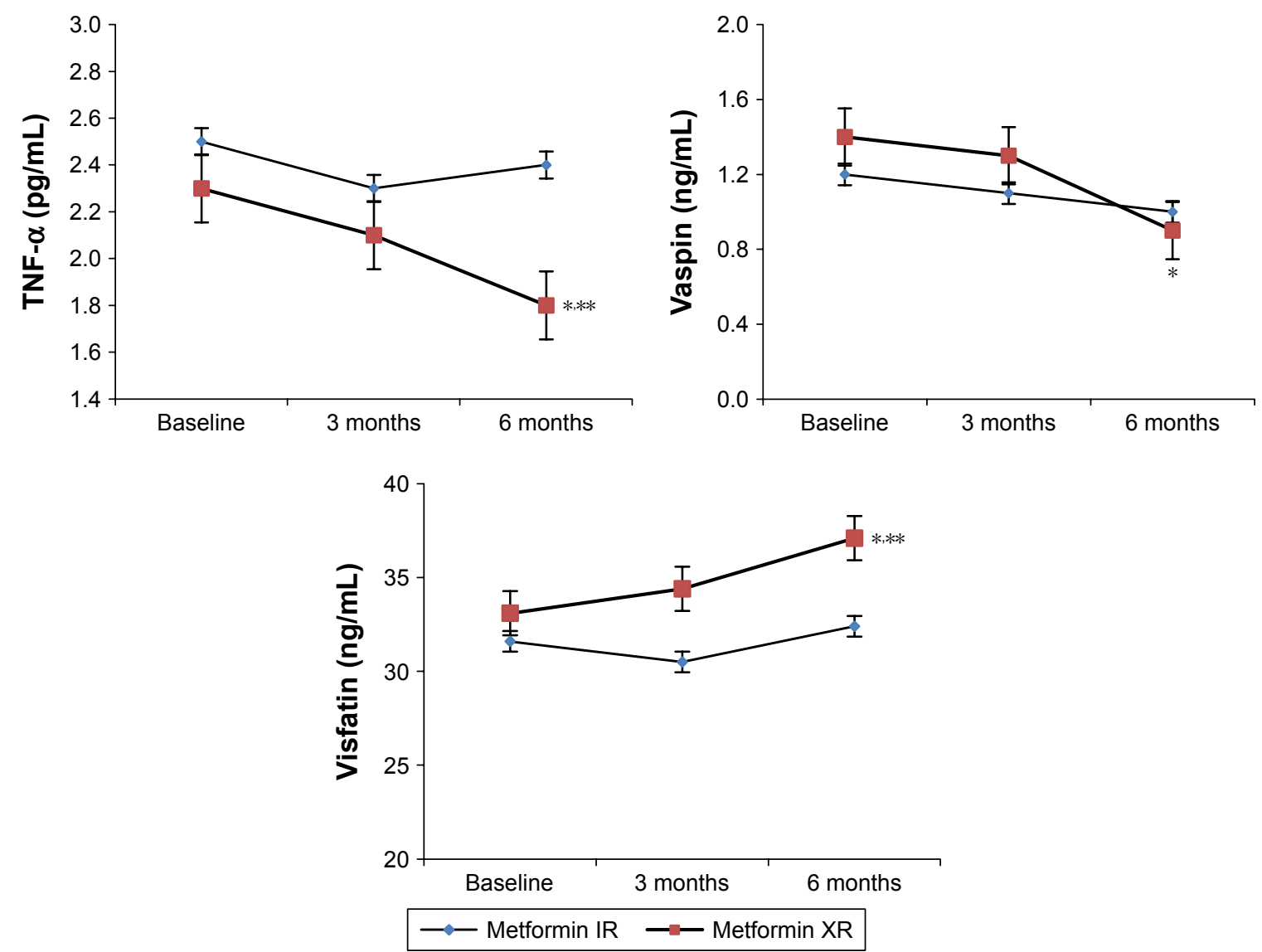

Figure 2 Adipocytokine modifications during the study with metformin immediate release and metformin extended release. Notes: Metformin IR dosage: $2,000 \pm I, 000 \mathrm{mg} /$ day; metformin XR dosage: I,000 $\pm 500 \mathrm{mg} /$ day. $* P<0.05$ vs 3 months with IR. **P<0.0I vs 3 months with IR. Abbreviations: IR, immediate release; XR, extended release; TNF- $\alpha$, tumor necrosis factor- $\alpha$.

The same can be said about lipid profile. We recorded an improvement in TC and LDL-C with metformin XR compared to IR: the positive effects of metformin on lipid profile have been already shown in rats, ${ }^{9}$ and we confirmed them in humans. We also observed a visfatin improvement with metformin XR, not recorded with metformin IR. Visfatin is a protein expressed by adipocytes and also by liver, muscle, bone marrow, and lymphocytes. ${ }^{10}$ Visfatin exerts insulin-mimetic effects in cultured adipocytes, hepatocytes, and myotubes and lowers plasma glucose in mice. ${ }^{11}$ Visfatin binds to the insulin receptor with similar affinity, but at a site distinct from insulin, with insulinsensitizing effects. ${ }^{12}$

At a first glance, it can appear strange that different formulations of the same molecule gave different results on the chosen end points; the improvement in glycemic factor in the case of metformin XR as compared to IR could be due to the constantly better control of blood sugar levels, while the IR may have exhibited the intermittent blood sugar control. Better or improved lipid and other levels may be the consequence of glycemic levels. Moreover, also a better patients' compliance (Figures 3 and 4 ) could partially explain the better effect of metformin XR. ${ }^{13}$

These data should not surprise, in fact, one of the factors that affect glycemic control is patient's compliance to therapy. Patients' compliance is correlated with the complexity of the treatment, to the total number of tablets taken daily, to the size of the tablets, to the difficulty in swallowing, to the side effects, and to the cost of therapy. ${ }^{14}$

Our results regarding adverse events were slightly different from that reported by Timmins et al, ${ }^{15}$ reporting that adverse events with metformin XR were similar to those reported with metformin IR. However, they did not directly compare the two different formulations, like we did; moreover, they conducted the study in healthy subjects and not in diabetics.

Regarding inflammatory markers, we recorded that TNF- $\alpha$ and Hs-CRP were lower with metformin XR compared to baseline and to metformin IR, this can be due to the better improvement in glycemic control obtained with metformin XR. It has already been shown that hyperglycemia induces endothelial damage $;{ }^{16}$ postprandial glycemia 

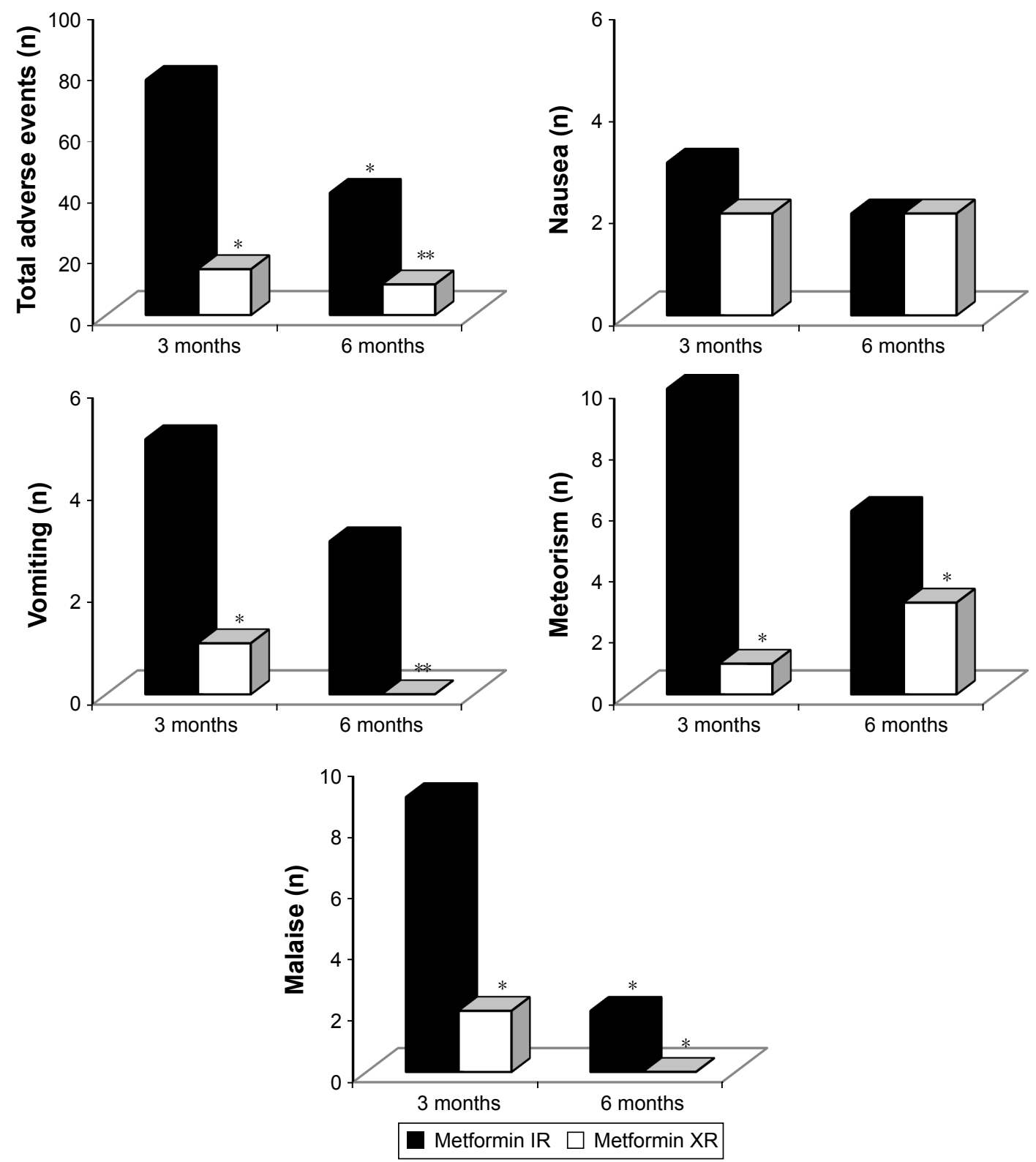

Figure 3 Adverse events with metformin immediate release and metformin extended release.

Notes: Metformin IR dosage: $2,000 \pm I, 000 \mathrm{mg} /$ day; metformin XR dosage: $1,000 \pm 500 \mathrm{mg} /$ day. $* P<0.05$ vs 3 months with IR. $* * P<0.01$ vs 3 months with IR. Abbreviations: IR, immediate release; $X R$, extended release.
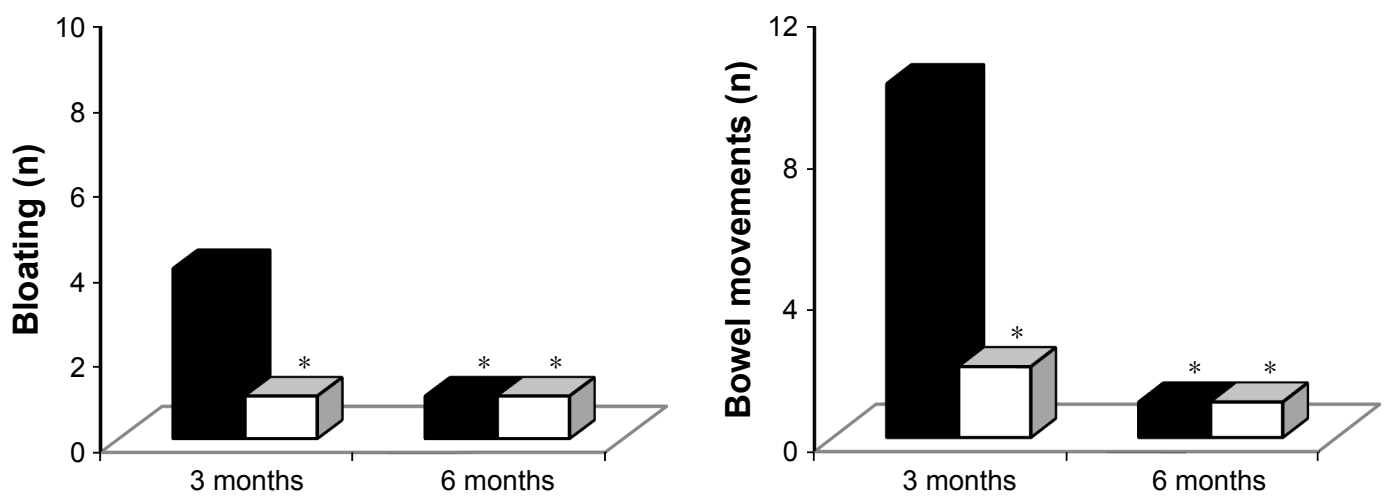

Figure 4 (Continued) 

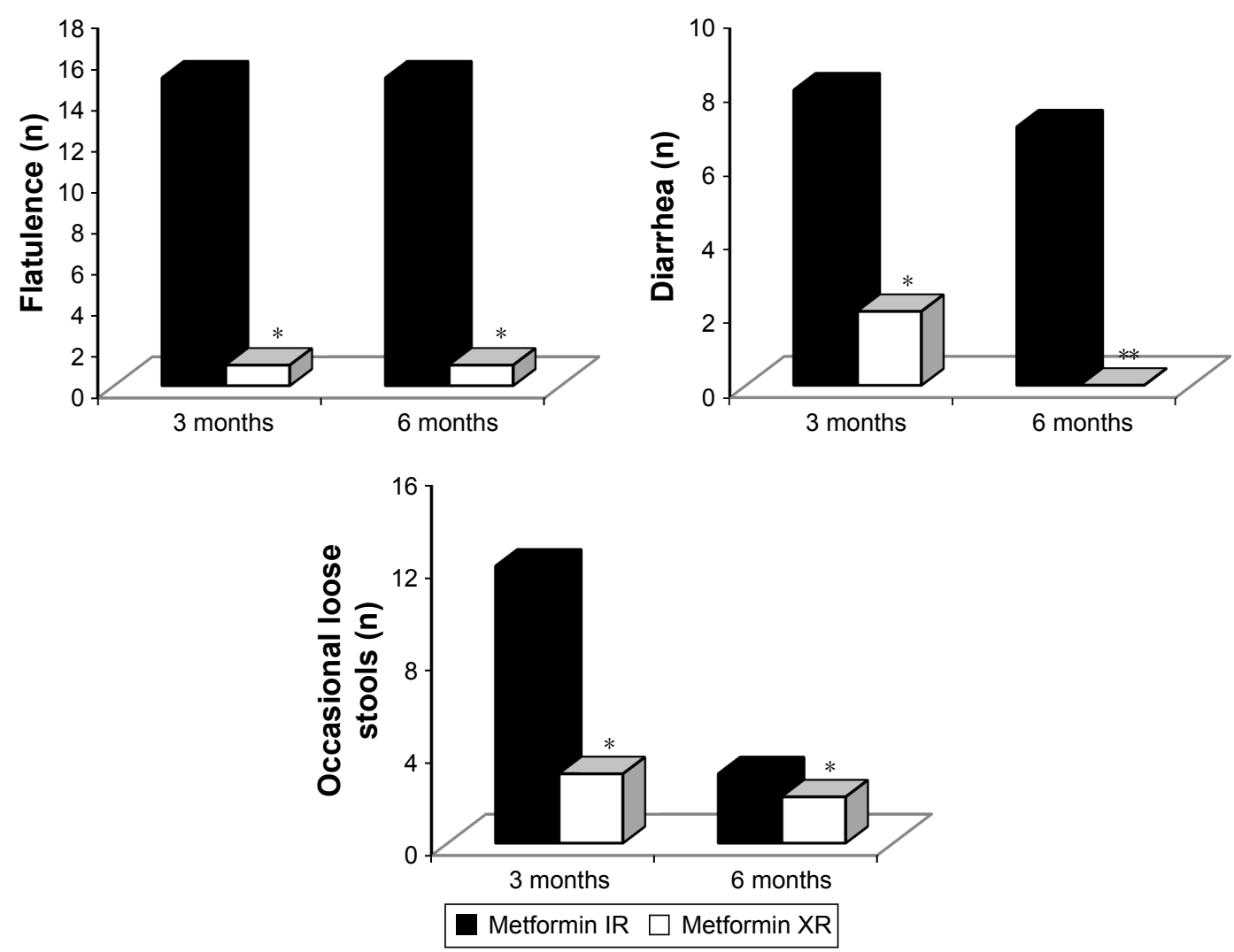

Figure 4 Adverse events with metformin immediate release and metformin extended release.

Notes: Metformin IR dosage: $2,000 \pm 1,000 \mathrm{mg} /$ day; metformin XR dosage: I, $000 \pm 500 \mathrm{mg} /$ day. $* P<0.05$ vs 3 months with IR. $* * P<0.0$ I vs 3 months with IR. Abbreviations: IR, immediate release; $X R$, extended release.

induces an acute, but repeated systemic inflammation that could influence the development of CVD in patients affected by disorders of glucose metabolism. ${ }^{17}$ Metformin XR better reduced glycemic control, with a consequent minor endothelial damage and a reduction of inflammatory markers.

A limitation of this study is that we used different doses of metformin XR and IR in each patient, according to the

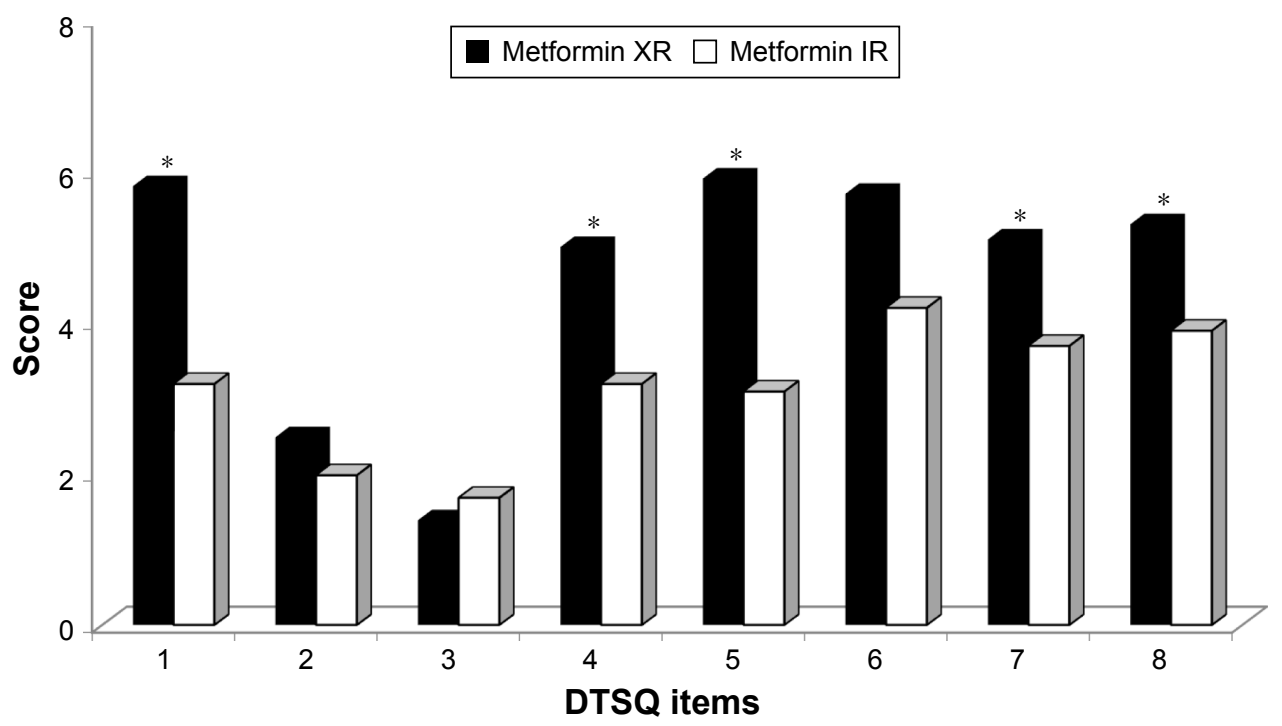

Figure 5 Diabetes Treatment Satisfaction Questionnaire (DTSQ) score with metformin IR and metformin XR. Note: $* P<0.05$ vs metformin IR.

Abbreviations: IR, immediate release; $X R$, extended release. 
patients' gastrointestinal tolerability; however, considering all the samples, both metformin XR and IR were used at an average dose $\pm 50 \%$ of the dose.

\section{Conclusion}

Metformin XR formulation seems to be more effective than metformin IR in improving glyco-metabolic control, lipid profile, and levels of some adipocytokines in patients with type 2 diabetes mellitus.

\section{Acknowledgments}

The authors have no relevant affiliations or financial involvement with any organization or entity with a financial interest in or financial conflict with the subject matter or materials discussed in the manuscript. This includes employment, consultancies, honoraria, stock ownership or options, expert testimony, grants or patents received or pending, or royalties. No writing assistance was used in the production of this manuscript.

\section{Disclosure}

The authors report no conflicts of interest in this work.

\section{References}

1. Hundal RS, Inzucchi SE. Metformin: new understandings, new uses. Drugs. 2003;63(18):1879-1894.

2. Derosa G, Romano D, Bianchi L, D’Angelo A, Maffioli P. Metformin powder formulation compared to metformin tablets on glycemic control and on treatment satisfaction in subjects with type 2 diabetes mellitus. J Clin Pharmacol. 2015;55(4):409-414.

3. Chacra AR. Evolving metformin treatment strategies in type-2 diabetes: from immediate-release metformin monotherapy to extended-release combination therapy. Am J Ther. 2014;21(3):198-210.

4. Rydén L, Standl E, Bartnik M, et al; Task Force on Diabetes and Cardiovascular Diseases of the European Society of Cardiology (ESC); European Association for the Study of Diabetes (EASD). Guidelines on diabetes, pre-diabetes, and cardiovascular diseases: executive summary. The task force on diabetes and cardiovascular diseases of the European Society of Cardiology (ESC) and of the European Association for the Study of Diabetes (EASD). Eur Heart J. 2007;28(1):88-136.
5. Lichtenstein AH, Appel LJ, Brands M, et al. Summary of American Heart Association Diet and Lifestyle Recommendations revision 2006. Arterioscler Thromb Vasc Biol. 2006;26(10):2186-2191.

6. Derosa G, Mugellini A, Pesce RM, D’Angelo A, Maffioli P. Barnidipine compared to lercanidipine in addition to losartan on endothelial damage and oxidative stress parameters in patients with hypertension and type 2 diabetes mellitus. BMC Cardiovasc Disord. 2016;16:66.

7. Derosa G, Querci F, Franzetti I, Dario Ragonesi P, D'Angelo A, Maffioli P. Comparison of the effects of barnidipine+losartan compared with telmisartan+hydrochlorothiazide on several parameters of insulin sensitivity in patients with hypertension and type 2 diabetes mellitus. Hypertens Res. 2015;38(10):690-694.

8. Derosa G, Bonaventura A, Bianchi L, et al. Effects of canrenone in patients with metabolic syndrome. Expert Opin Pharmacother. 2013; 14(16):2161-2169.

9. Gao Y, Wang C, Pan T, Luo L. Impact of metformin treatment and swimming exercise on visfatin levels in high-fat-induced obesity rats. Arq Bras Endocrinol Metabol. 2014;58(1):42-47.

10. Fukuhara A, Matsuda M, Nishizawa M, et al. Visfatin: a protein secreted by visceral fat that mimics the effects of insulin. Science. 2005; 307(5708):426-430.

11. Hug C, Lodish HF. Medicine. Visfatin: a new adipokine. Science. 2005; 307(5708):366-367.

12. Skop V, Kontrová K, Zídek V, et al. Autocrine effects of visfatin on hepatocyte sensitivity to insulin action. Physiol Res. 2010;59(4):615-618.

13. Ali S, Fonseca V. Overview of metformin: special focus on metformin extended release. Expert Opin Pharmacother. 2012;13(12): $1797-1805$.

14. Melikian C, White TJ, Vanderplas A, Dezii CM, Chang E. Adherence to oral antidiabetic therapy in a managed care organization: a comparison of monotherapy, combination therapy, and fixed-dose combination therapy. Clin Ther. 2002;24(3):460-467.

15. Timmins P, Donahue S, Meeker J, Marathe P. Steady-state pharmacokinetics of a novel extended-release metformin formulation. Clin Pharmacokinet. 2005;44(7):721-729.

16. Derosa G, D'Angelo A, Salvadeo SA, et al. Oral glucose tolerance test effects on endothelial inflammation markers in healthy subjects and diabetic patients. Horm Metab Res. 2010;42(1):8-13.

17. Ruotsalainen E, Vauhkonen I, Salmenniemi U, et al. Markers of endothelial dysfunction and low-grade inflammation are associated in the off spring of type 2 diabetic subjects. Atherosclerosis. 2008; 197(1):271-277.
Drug Design, Development and Therapy

\section{Publish your work in this journal}

Drug Design, Development and Therapy is an international, peerreviewed open-access journal that spans the spectrum of drug design and development through to clinical applications. Clinical outcomes, patient safety, and programs for the development and effective, safe, and sustained use of medicines are the features of the journal, which

\section{Dovepress}

has also been accepted for indexing on PubMed Central. The manuscript management system is completely online and includes a very quick and fair peer-review system, which is all easy to use. Visit http://www.dovepress.com/testimonials.php to read real quotes from published authors. 